\& Tait, 1968). The present work was undertaken to show that the biological effects of oestrone on rat and rabbit uterus in vitro can be related to the ability of the tissue to convert oestrone into oestradiol.

The effects of oestrone and oestradiol on rat and rabbit uterus were assessed initially by examining the histology of explants cultured for 3 days in Eagle's medium at $37^{\circ}$ with a gas phase of $\mathrm{N}_{\mathbf{2}}+$ $\mathrm{O}_{2}+\mathrm{CO}_{2}$ (25:70:5). The most sensitive indicator of oestrogenic action under these conditions was the state of the epithelial cells of the glands and lumen. Oestradiol was able to maintain the structure of both rat and rabbit uterus, $0 \cdot 1 \mu \mathrm{M}$ being the optimum concentration of hormone in the medium. Oestrone $(1 \cdot 0 \mu \mathrm{M})$ was as effective as oestradiol in maintaining the uterus of the rabbit.

These conclusions were supported by results from a second set of experiments in which the biochemical viability of the explants was determined by their ability to incorporate labelled glucose into acid-soluble nucleotides, lipids, RNA, DNA and proteins. Both oestrone and oestradiol caused significant stimulation in the glucose metabolism of rabbit uterus cultured for 3 days, compared with material cultured in the absence of oestrogen. In the rat only oestradiol had a stimulatory effect on glucose metabolism; there was no significant difference between material cultured with oestrone and in the absence of hormone.

This species difference in the response of uterine tissue to oestrone can be related to the presence of oestrone $17 \beta$-reductase in rabbit uterus but not that of rat (Macartney \& Thomas, 1969). Analysis of the labelled steroids in explants cultured in the presence of $\left[4-{ }^{-14} \mathrm{C}\right]$ oestrone and $\left[4-{ }^{14} \mathrm{C}\right]$ oestradiol indicates that the biological effects of oestrone are derived from its conversion into oestradiol in the rabbit uterus.

S.L.R. holds a Medical Research Council Scholarship.

Baird, D., Horton, R., Longcope, C. \& Tait, J. F. (1968). Perspect. Biol. Med. 11, 384.

Macartney, J. C. \& Thomas, G. H. (1969). J. Endocrin. 43, 247.

Effects of Thyroid Hormones on Oxidative Phosphorylation and on 11 $\beta$-Hydroxylation of Ox Adrenal-Gortex Mitochondria

By R. Michel, J. Bouhnik and O. Mrches. (Endocrinologie, Facultéde Pharmacie and Biochimie, Collège de France, Paris, France)

Previous studies showed that 2,4-dinitrophenol uncouples oxidative phosphorylation and decreases corticosterone synthesis from deoxycorticosterone by adrenal-cortex mitochondria (Guerra, Péron
\& McCarthy, 1966). Thyroid hormones exhibited uncoupling properties on mitochondria from several tissues (Hoch, 1966; Michel \& Leblanc, 1969), but, in contrast with 2,4-dinitrophenol, whose inhibitory doses in state 3 are higher than those that stimulate state 4, their opposite effects were obtained with the same doses. Our work was performed in order to study the effects of thyroid compounds on the functions of adrenal-cortex mitochondria.

The ox particles were prepared as described by Cammer \& Estabrook (1967). Iodothyronines affected the oxidative phosphorylation of adrenalcortex mitochondria in the same manner as those of other organs; with succinate or malate in state 4 the respiration increased at low doses but decreased at high doses. In state 3 the inhibition was observed at any concentration. Thyroid hormones also decreased the rate of oxygen consumption in the presence of deoxycorticosterone and simultaneously lowered the synthesis of corticosterone. In the same conditions 2,4-dinitrophenol increased respiration but lowered the $11 \beta$-hydroxylation. The respiratory action of L-thyroxine was dependent on the substrate concentration, but the responses differed in the presence of both $\mathrm{ADP}$ and deoxycorticosterone. The plot of the reciprocal of the oxygen consumption rate against the reciprocal of the substrate concentration showed that the curves obtained with or without L-thyroxine were straight lines converging on the ordinates with deoxycorticosterone and on the abscissa with ADP.

It was known that the steroid conversion required NADPH. In one hypothesis Purvis, Battu \& Péron (1968) considered that the energy would be generated by a transhydrogenase. The results we obtained with 2,4-dinitrophenol and L-thyroxine may support this suggestion. However, according to another hypothesis (Simpson \& Estabrook, 1969), 2,4-dinitrophenol would prevent NADPH synthesis by inhibiting the mitochondrial 'malic' enzyme. The quantitative experiments performed with different substrate concentrations showed that inhibition by L-thyroxine was in accordance with the Michaelis law with both ADP and deoxycorticosterone. The effect was uncompetitive with the phosphate acceptor but competitive with the steroid. The inhibition of corticosterone synthesis probably takes place mainly on the mitochondrial 'malic' enzyme, whereas the action of thyroid hormones on oxidative phosphorylation seems to be more complex.

Cammer, W. \& Estabrook, R. W. (1967). Arch. Biochem. Biophys. 122, 721.

Guerra, F., Péron, F. G. \& McCarthy, J. L. (1966). Biochim. biophys. Acta, 117, 433.

Hoch, F. L. (1966). J. biol. Chem. 241. 524.

Michel, R. \& Leblanc, A. (1969). Bull. Soc. Chim. biol., Paris, 51, 355. 
Purvis, J. L., Battu, R. G. \& Péron, F. G. (1968). In Functions of the Adrenal Cortex, p. 1007. Ed. by McKerns, K. W. Amsterdam: North Holland Publishing Co.

Simpson, E. R. \& Estabrook, R. W. (1969). Arch. Biochem. Biophys. 129, 384.

Changes in Mitochondrial Structure and Ribosomal Activity in Muscle as a Consequence of the Interaction between a Glucocorticoid and some Anabolic Steroids

By G. R. Bullock, R. F. Peters and A. M. White. (CIBA Laboratories Ltd., Horsham, Sussex)

When adult male rats were treated with a single dose of triamcinolone acetonide $(20 \mathrm{mg}$. $/ \mathrm{kg}$.) changes in the mitochondria of the thigh muscles were seen under the electron microscope that became most marked about $12 \mathrm{hr}$. after injection of the drug. Myelin figures and whorls were apparent when the muscle was fixed in $5 \%(\mathrm{v} / \mathrm{v})$ glutaraldehyde and post-fixed in $1 \%(\mathrm{w} / \mathrm{v}) \mathrm{OsO}_{4}$, but this type of damage was not seen when the fixation media were made $2 \mathrm{mM}$ with respect to $\mathrm{Ca}^{2+}$, nor when the muscle was stretch-fixed directly in $\mathrm{OsO}_{4}$ for $2 \mathrm{hr}$. Extremely large mitochondria were seen independently of the fixation method in some fibres, whereas in others the mitochondria disappeared completely. The mitochondria were not swollen. Some morphological changes were seen as early as $2 \mathrm{hr}$. after triamcinolone administration. Throughout the $24 \mathrm{hr}$. period the rest of the tissue remained unaltered.

When the animals were pretreated with testosterone $(5 \mathrm{mg} . / \mathrm{kg}$.) daily for 3 days and then given triamcinolone acetonide (20 mg./kg.), enlarged mitochondria were seen after $12 \mathrm{hr}$. in even greater numbers than in animals receiving triamcinolone acetonide alone, and muscle glycogen rose to $3 \cdot 7$ times the control value compared with 2.8 times the control value when only the anti-inflammatory steroid was given. The activity of muscle ribosomes from the same animals was decreased after $12 \mathrm{hr}$. to the same extent as with triamcinolone alone, i.e. to about $75 \%$ of control value. Pretreatment with the anabolic steroid Ba-36644 had no effect on the enlarged mitochondria, but the activity of muscle ribosomes was partially restored to normal. In contrast, pretreatment with methandienone (Dianabol) (5 mg./kg.) enabled normal ribosomal function to be retained, together with normal mitochondrial morphology, after the animals had received triamcinolone acetonide. Again, however, there was no effect on the glucocorticoid-induced rise in muscle glycogen.

Since methandienone would have less androgenic action than testosterone (Desaulles, Krahenbühl, Schuler \& Bein, 1959) or Ba-36644 (Desaulles \&
Schär, 1967) at the dosages used, these results show that the ability of an anabolic steroid to counteract the effects of a glucocorticoid is probably not a function of its androgenicity. A similar conclusion from chronic studies in rabbits (Bullock, White \& Worthington, 1968) is therefore substantiated.

Bullock, G., White, A. M. \& Worthington, J. (1968). Biochem. J. 108, 417.

Desaulles, P. A., Krahenbühl, C., Schuler, W. \& Bein, H. J. (1959). Schweiz. med. Wschr. 89, 1313.

Desaulles, P. A. \& Schär, B. (1967). Proc. 2nd int. Congr. Hormonal Steroids: Excerpta med. Found. int. Congr. Ser. no. 132, p. 541.

\section{Purification of an Oestrophilic Protein from Calf Uterus}

By E. R. De Sombre, G. A. Puca and E. V. JENSEN (introduced by K. GrIFriths). (Ben May Laboratory for Cancer Research, University of Chicago, Chicago, Ill., U.S.A.)

A method has been devised for purifying the oestrogen-binding protein ('uptake receptor') of uterine cytosol that circumvents the marked tendency of this receptor to aggregate during attempted isolation. Ammonium sulphate precipitation of the oestradiol-receptor complex of calf uterine cytosol in the presence of $\mathrm{Ca}^{2+}$ yields both an $8 \mathrm{~s}$ complex and its $4 \mathrm{~s}$ subunit, which are stable during further fractionation by gel filtration and ion-exchange chromatography. The major product is the $4 \mathrm{~s}$ complex, which does not revert to the $8 \mathrm{~s}$ form in the absence of salt and which has been purified 5000 -fold to yield receptor protein of about $4 \%$ purity. The elution volumes from Sephadex G-200 indicate molecular weights of approx. 200000 for the $8 \mathrm{~s}$ complex and 75000 for the $4 \mathrm{~s}$ subunit; on isoelectric focusing these partially purified complexes show isoelectric points of 5.8 and 6.4 respectively. In sucrose gradients containing $\mathrm{KCl}$, the purified $4 \mathrm{~s}$ complex sediments at a lower rate than does the $5 \mathrm{~s}$ oestradiol-receptor complex extracted from the nuclei of calf uterine horns exposed to dilute solutions of tritiated oestradiol at $37^{\circ}$ in vitro.

Although the receptor protein is less stable when not complexed with oestradiol, rapid purification, by salt precipitation and ion-exchange chromatography, of calf uterine cytosol containing $\mathrm{Ca}^{2+}$ but no oestradiol furnished the uncomplexed $4 \mathrm{~s}$ subunit. When exposed to oestradiol, this protein showed strong saturable binding, similar in all respects to that of the original cytosol fraction and inhibited both by hexoestrol and by nafoxidine. Thus the stable $4 \mathrm{~s}$ subunit appears to be closely related to the oestrophilic portion of the $8 \mathrm{~s}$ receptor protein. 